\title{
Neurohumoral, immunoinflammatory and cardiovascular profile of patients with severe tetanus: a prospective study Janete $S$ Brauner ${ }^{1}$ and Nadine Clausell*2
}

\author{
Address: ${ }^{1}$ Intensive Care Units from Hospital Nossa Senhora da Conceição and Hospital de Clínicas de Porto Alegre, Rua Ramiro Barcelos, 2350/ \\ 2060, CEP 90035-003, Porto Alegre, RS, Brazil. Graduate Program in Cardiology and Cardiovascular Sciences, Universidade Federal do Rio Grande \\ do Sul, Porto Alegre, RS, Brazil and ${ }^{2}$ Graduate Program in Cardiology and Cardiovascular Sciences, Universidade Federal do Rio Grande do Sul, \\ Porto Alegre, RS, Brazil \\ Email: Janete S Brauner - j.orlofe@terra.com.br; Nadine Clausell* - clausell@portoweb.com.br \\ * Corresponding author
}

Published: 17 February 2006

Journal of Negative Results in BioMedicine2006, 5:2 doi:10.1 I86/1477-575I-5-2

This article is available from: http://www.jnrbm.com/content/5/I/2

(c) 2006Brauner and Clausell; licensee BioMed Central Ltd.

This is an Open Access article distributed under the terms of the Creative Commons Attribution License (http://creativecommons.org/licenses/by/2.0), which permits unrestricted use, distribution, and reproduction in any medium, provided the original work is properly cited.
Received: 04 January 2006

Accepted: 17 February 2006

\begin{abstract}
Introduction: Autonomic disturbances in tetanus are traditionally associated with adrenergic variations and/or cardiac dysfunction, based on case report data. The objective of this study was to measure catecholamines, (TNF)- $\alpha$ and troponin T relative to and left ventricular ejection fraction (LVEF) in patients with severe tetanus.

Methods: This prospective study was carried out at two general Intensive Care Units and included 21 patients consecutively admitted with severe tetanus. Catecholamines (dopamine, norepinephrine, epinephrine and total catecholamines), tumor necrosis factor (TNF)- $\alpha$ and LVEF were assessed during the first week of autonomic instability and following tetanus recovery. Troponin $\mathrm{T}$ was measured during autonomic instability only.

Results: Mean age of patients was $46 \pm 17$ years, median Acute Physiology and Chronic Health Evaluation II (APACHE II) score was 8 (range I-23). All patients had both blood pressure and heart rate instability. Two patients were recuperated from cardiac arrest. Intensive Care Unit mortality was $14 \%$ (3 cases). No increase in total catecholamines or in TNF- $\alpha$ levels was observed during autonomic instability or in the recovery period. Six patients had troponin $T>0.01 \mathrm{ng} / \mathrm{ml}$ and six had $>0.1 \mathrm{ng} / \mathrm{ml}$. Mean LVEF was similar during autonomic instability and after tetanus recovery, $67 \pm 7 \%$ and $65 \pm 7 \%$, respectively. Troponin T levels correlated with pressoric instability during autonomic instability.

Conclusion: Our study demonstrated that in patients with severe tetanus no significant increased levels of catecholamines or TNF- $\alpha$ or evidence of cardiac systolic dysfunction was observed either during autonomic instability or in the recovery period. Elevated values of troponin $\mathrm{T}$ detected during autonomic instability were not associated with left ventricular dysfunction. Our data do not support the hypothesis that autonomic disturbances in tetanus are associated with adrenergic variations or cardiac dysfunction.
\end{abstract}

\section{Introduction}

Autonomic dysfunction, sudden death and complications of prolonged critical disease, such as nosocomial infections, thromboembolism and gastrointestinal bleeding 
are main causes of death in tetanus [1]. In a previous study we showed that autonomic instability occurred in $100 \%$ of patients with tetanus, and that $35 \%$ of deaths were timely associated with the symptomatic period, cardiac arrest and hypotension, and inversely associated with the duration of the onset period [2].

Autonomic instability as defined by Kerr et al., is a characteristic syndrome whose features include sustained but labile hypertension and tachycardia, irregularities of cardiac rhythm, peripheral vascular constriction, profuse sweating, pyrexia, increased carbon dioxide output, increased urinary catecholamine excretion, and, in some cases, the development of hypotension [3]. Severe hypertension and tachycardia may alternate with profound hypotension and bradycardia, suggesting intense sympathetic activity $[3,4]$. Accordingly, both increased urinary and plasmatic levels of catecholamines have been described in this setting $[3,5]$. Other authors, however, found normal excretion and plasma catecholamine levels in patients with tetanus $[5,6]$, indicating that an association between elevated catecholamine levels and autonomic instability remains to be further documented. Bradycardia is also occasionally noticed, which suggests parasympathetic system or basal nucleus dysfunction, leading to excessive vagal activity $[7,8]$.

Prolonged stimulation of the sympathetic nervous system or the continuous release of catecholamines may cause vascular and myocardial damage $[9,10]$. However, histologic evidence of myocardial necrosis in tetanus was demonstrated in few cases [11]. It was suggested that either a sudden loss of catecholamine stimulation or myocardial damage caused by the direct action of the tetanus toxin, could be involved in cardiac dysfunction described in tetanus $[12,13]$. However, an invasive hemodynamic study involving 27 patients with severe tetanus showed a hyperdynamic profile rather than depressed cardiac function [14]. Since it is well known that myocardial damage caused by catecholamines can induce synthesis of cytokines by myocytes [15,16], cytokines, specifically those with known cardiodepressant properties such as TNF- $\alpha$, could be an alternative mechanism involved in cardiac dysfunction, in the setting of tetanus.

The objective of the present study was to evaluate the temporal behavior of catecholamines and of TNF- $\alpha$ relative to left ventricular ejection fraction obtained by two-dimensional transthoracic echocardiography at two time points: during autonomic instability and after recovery from tetanus. Levels of the troponin T were used to identify potential myocardial damage in the period of autonomic instability. In this report our data failed to indicate associations between adrenergic and cytokine activation with changes in cardiac performance in patients with tetanus.

\section{Methods}

\section{Study population}

This cohort study included all patients with a diagnosis of severe tetanus characterized by marked rigidity, frequent generalized spasms, dysphagia, respiratory compromise or apnea according to the modified Abblett's scale, $[17,18]$ consecutively admitted to the ICU of two general hospitals (Hospital Nossa Senhora da Conceição and Hospital de Clínicas de Porto Alegre, Brazil). Data were prospectively collected without interference in management. Patients with other potential causes of hemodynamic instability such as septic shock were excluded from the study. The study was approved by the Ethics Committees from both hospitals. Patients' legal representatives signed an informed consent document prior to enrolment. A portion of this population was part of the entire cohort of our previous study reporting demographics and prognosis of patients with tetanus [2].

The main variables of the study were: plasma catecholamines, TNF- $\alpha$, troponin $\mathrm{T}$ levels and transthoracic echocardiographic-based LVEF. These variables were assessed both during the autonomic instability and after recovery from tetanus, with the exception of troponin $\mathrm{T}$, only measured during autonomic instability. The following variables were also recorded: age, sex, APACHE II score in the first 24 hrs of ICU admission, temporal development of symptoms, periods of the disease (incubation period, onset period, symptomatic period), clinical characteristics, clinical and infectious complications and electrocardiogram (EKG).

\section{Evaluation of autonomic profile, catecholamine levels and TNF- $\alpha$}

Autonomic instability was characterized by the presence of blood pressure and heart rate lability, arrhythmias and/ or cardio respiratory arrest recorded by continuous noninvasive monitoring (monitor 66S, Hewlett-Packard, USA), as reported previously [2]. Variation from minimum to maximum (delta) of blood pressure and of heart rate was recorded in both periods.

At the end of the first week of autonomic instability and after recovery from tetanus, $10 \mathrm{ml}$ blood sample was collected into an EDTA-containing tube and kept under refrigeration. Samples were immediately centrifuged at $5^{\circ} \mathrm{C}$, plasma was placed in $1.5 \mathrm{ml}$ Eppendorf tubes and stored at $-80^{\circ} \mathrm{C}$ for later measurement of plasma catecholamines and TNF- $\alpha$ levels. Catecholamine levels (epinephrine, norepinephrine, dopamine and total catecholamines) were measured at CRIESP laboratory (São Paulo, Brazil) using high performance liquid chromatography (HPLC). Commercially available Elisa assays were used to measure TNF- $\alpha$ plasma levels using duplicate samples to minimize inter-assay variability. Lower detec- 
Table I: Clinical and laboratory findings during autonomic instability at time of collection.

\begin{tabular}{|c|c|c|c|c|c|c|c|c|c|}
\hline Patient & Age & APACHE & MBP & HR & CREAT & TROP T & Infection & Germ & AB \\
\hline MAPRR & 20 & 6 & 145 & 129 & 0.8 & $<0.01$ & Blood & S. aureus & vancomycin \\
\hline VPO & 48 & 3 & 110 & 127 & I.I & 0.012 & - & - & penicillin \\
\hline MSR & 54 & 4 & 49 & 109 & 0.5 & 0.07 & respiratory central line & S. aureus & vancomycin \\
\hline$J P$ & 50 & 8 & 84 & 124 & 0.6 & $<0.01$ & respiratory & $?$ & cefuroxime \\
\hline JRS & 74 & 10 & 78.6 & 122 & 1.4 & 0.306 & - & - & penicillin \\
\hline ESB & 19 & 6 & 62 & 81 & 0.8 & $<0.01$ & - & - & penicillin \\
\hline CEO & 53 & 8 & 78.6 & 92 & 0.5 & 0.135 & respiratory & S. aureus & vancomycin \\
\hline RAB & 57 & 6 & 69 & 74 & I.I & 0.015 & - & - & penicillin \\
\hline JOR & 57 & 15 & 100.6 & 129 & 1.0 & 0.028 & osteomyelitis & - & ofloxa, metro \\
\hline JBS & 48 & 10 & 90 & 98 & 0.7 & 0.02 & - & - & penicillin \\
\hline GS & 36 & 11 & 67 & 96 & 1.0 & 0.045 & respiratory & S. aureus & vancomycin \\
\hline SBD & 33 & 15 & 88 & 71 & 0.8 & 0.105 & respiratory & $?$ & cefipime \\
\hline LCCM & 48 & 4 & 93.6 & 62 & 0.6 & $<0.01$ & respiratory & P. mirabilis & ampisulbact \\
\hline $\mathrm{MJO}$ & 29 & I & 87 & 88 & 0.7 & $<0.01$ & - & - & penicillin \\
\hline JCWV & 20 & 5 & 290 & 133 & 0.7 & $<0.01$ & respiratory & $?$ & ampisulbact \\
\hline IMR & 60 & 23 & 66 & 86 & 0.7 & $<0.01$ & respiratory & P. aeruginosa & ampisulbact \\
\hline MS & 70 & II & 48.3 & 78 & I.I & 0.137 & Blood & S. aureus & vancomycin \\
\hline ER & 44 & II & 75 & 81 & I.I & 0.135 & Blood & S. epidermitis & oxacillin \\
\hline LSLF & 36 & 10 & 70 & 100 & 1.0 & $<0.01$ & - & - & ampicillin \\
\hline MLS & 82 & 21 & 24 & 92 & 1.5 & 0.2135 & - & - & penicillin \\
\hline JS & 44 & 2 & 126 & 75 & 1.0 & $<0.01$ & - & - & penicillin \\
\hline Mean (SD) & $46.7(17.2)$ & $9(5.7)$ & $81.3(26.7)$ & $97.4(22.1)$ & $0.9(0.2)$ & $0.6(0.08)$ & & & \\
\hline
\end{tabular}

$\mathrm{SD}=$ standard deviation; $\mathrm{MBP}=$ mean blood pressure; $\mathrm{HR}=$ heart rate; $\mathrm{CREAT}=$ creatinine; $\mathrm{TROP} \mathrm{T}=\operatorname{troponin} \mathrm{T} ; \mathrm{AB}=$ antibiotic $($ ofloxa $=$ ofloxacin; ampisulbact = ampicillin/sulbactam; metro = metronidazole).

tion limits of the assay were typically less than $4.4 \mathrm{pg} / \mathrm{ml}$ (R \& D Systems, Minneapolis, MN, USA).

\section{Troponin $T$ levels during autonomic instability}

During autonomic instability, blood samples collected were also used for measurement of plasma troponin T levels using a sandwich electrochemiluminescence immunoassay (ECLIA), Elecsys Troponin T STAT (Roche, Germany). Detection band ranges from $0.01 \mathrm{ng} / \mathrm{ml}$ to 25 $\mathrm{ng} / \mathrm{ml}$ in this assay. In $99 \%$ of healthy volunteers, the cutoff point was lower than $0.01 \mathrm{ng} / \mathrm{ml}$, and the cutoff point for myocardial infarction was $0.1 \mathrm{ng} / \mathrm{ml}$ [19-21].

\section{Transthoracic echocardiography functional evaluation}

Two-dimensional color Doppler transthoracic echocardiography was performed at the two collection time points (autonomic instability and after recovery period) to measure LVEF by the M-mode (Teicholtz method), in accordance to the recommendations of the American Society of Echocardiography. Whenever possible, hemodynamic status of patients were kept at the best possible care according to the ICU protocols in order to avoid confounding load variables interfering with ejection fraction measurements. Simultaneously to echocardiogram, blood pressure and heart rate were recorded as well as blood sampling to measure biological variables. Additional echocardiography-based cardiac findings were also recorded. Data were recorded and later re-evaluated by another blinded echocardiographist.

\section{Statistical analysis}

Continuous variables are described as means and standard deviation or medians and range; categorical variables are described by frequency tables and proportions. Magnitude of variation from minimum to maximum values of variables (heart rate and blood pressure) were calculated and expressed as delta values. Discrimination between parametric and non-parametric variables was performed using histograms and the Kolmogorov-Smirnov test. Student $t$ test was used to compare continuous and normally distributed variables; Mann Whitney test was used for asymmetric continuous variables, and the chi-square test for categorical variables. Paired samples $t$ tests and Wilcoxon test were used to compare continuous variables during and after autonomic instability. Pearson and Spearman tests were used to evaluate correlation between variables. Significance level was established at $\mathrm{p}<0.05$ for all comparisons.

\section{Results}

\section{Clinical characteristics}

We evaluated 21 patients with severe tetanus, 18 (84\%) males, mean age $46 \pm 17$ years, with median APACHE II score of 8 (range - 1-23). Incubation period was $7.0 \pm 4$ days, onset period was $3 \pm 3$ days and symptomatic period was $40 \pm 10$ days. All patients were mechanically ventilated (mean $41 \pm 12$ days) and the length of stay in the ICU was $45 \pm 13$ days. ICU mortality rate was $14 \%$ (three patients), thus 18 patients underwent after recovery 


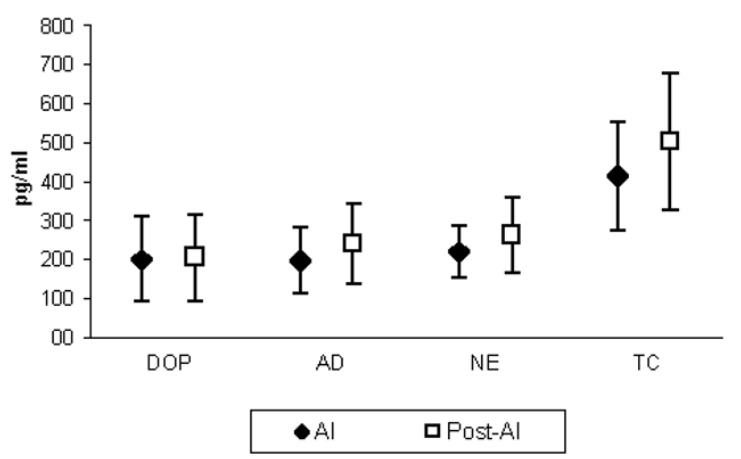

Figure I

Levels of different catecholamines $(\mathrm{pg} / \mathrm{ml})$ at the two collection time points. Mean and standard deviation values. $\mathrm{DOP}=$ dopamine; $A D=$ epinephrine; $N E=$ norepinephrine; $T C=$ total catecholamines; $\mathrm{Al}=$ autonomic instability; Post-AI = after recovery from tetanus.

assessments. Seven patients had chronic obstructive pulmonary disease, six had history of alcohol abuse, three had hypertension, and three had history of coronary artery disease. Patients received diazepam (mean dose $=$ $33.9 \pm 8.0 \mathrm{mg} / \mathrm{h}$ ), pancuronium (mean dose $=0.8 \pm 0.08$ $\mathrm{mg} / \mathrm{kg} / \mathrm{h}$ ) and morphine (median dose $=3 \mathrm{mg} / \mathrm{h}$; range 0-20) intravenously, continuously. In addition to drugs used for sedation, seven patients also received clonidine $0.150 \mathrm{mg} /$ day. All patients received antibiotics - nine for tetanus only, and 12 for other infections also. The most frequent clinical and infectious complications were: pulmonary atelectasis $(57 \%)$, renal failure $(24 \%)$, respiratory infection $(90 \%)$, urinary infection $(81 \%)$, and central line

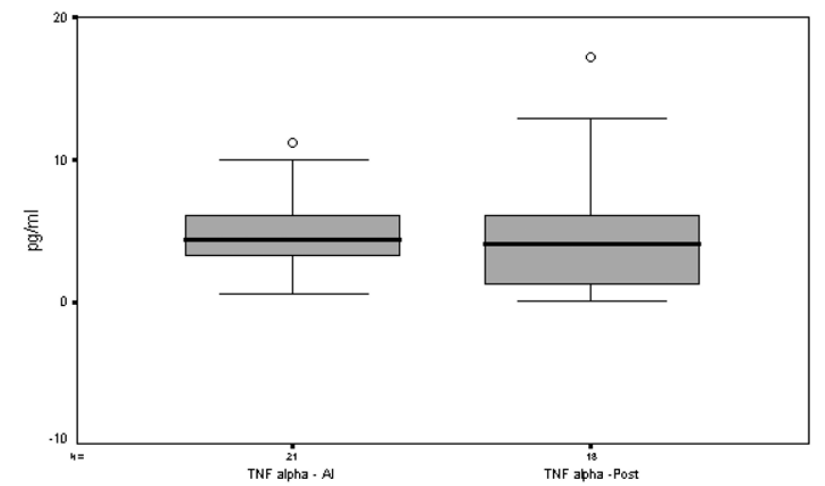

\section{Figure 2}

Box plot graph comparing TNF- $\alpha$ levels $(\mathrm{pg} / \mathrm{ml})$ at the two collection time points. Median and percentile values $\left(25^{\text {th }}\right.$ and $\left.75^{\text {th }}\right) . \mathrm{Al}=$ autonomic instability; Post-Al $=$ after recovery from tetanus. infection (38\%). Individual clinical characteristics are shown in Table 1.

\section{Autonomic profile}

All patients had autonomic instability characterized by blood pressure or heart rate variation, other arrhythmias or cardiac arrest. During autonomic dysfunction, mean maximum heart rate was $143 \pm 17 \mathrm{bpm}$ and mean minimum heart rate was $59 \pm 18 \mathrm{bpm}$. Ten patients had marked bradycardia (two had third degree AV block requiring pacemaker implants), two had recuperated cardiac arrest and one had atrial fibrillation. Mean blood pressure during hypertension periods ranged from 109 to $199 \mathrm{mmHg}$ and from 15 to $73 \mathrm{mmHg}$ during hypotension periods.

\section{Catecholamine levels}

Catecholamine concentrations were measured during the first week of autonomic instability and after recovery from tetanus. When plasma concentrations in the two periods were compared, we observed that levels of epinephrine $(195 \pm 83$ versus $239 \pm 105 \mathrm{pg} / \mathrm{ml})$, norepinephrine $(218$ \pm 88 versus $261 \pm 96 \mathrm{pg} / \mathrm{ml})$, dopamine (198 \pm 109 versus $204 \pm 111 \mathrm{pg} / \mathrm{ml})$ and total catecholamines $(414 \pm 138$ versus $500 \pm 174 \mathrm{pg} / \mathrm{ml}$ ) tended to be higher after recovery from tetanus, although within normal limits (Figure 1). Individual measurements showed levels above normal for dopamine in 11 patients, epinephrine in three patients, and norepinephrine in one patient during autonomic instability.

\section{TNF- $\alpha$ levels}

Levels of TNF- $\alpha$ showed similar median plasma concentrations in both periods, i.e. 4.5 (range -2.7-6.7) $\mathrm{pg} / \mathrm{ml}$ and 4.1 (range $-1.2-6.8$ ) $\mathrm{pg} / \mathrm{ml}$ in autonomic instability and after tetanus recovery, respectively p > 0.05 (Figure 2). Plasma levels of $<15.6 \mathrm{pg} / \mathrm{ml}$ were considered within normal expected values, according to the manufacturer.

\section{Troponin $T$ concentrations and electrocardiogram}

Analysis of plasma troponin $\mathrm{T}$ concentrations during autonomic instability revealed that nine patients had values lower than $0.01 \mathrm{ng} / \mathrm{ml}$, and that 12 had values greater than $0.01 \mathrm{ng} / \mathrm{ml}$. Of these, six patients had troponin $\mathrm{T}$ concentrations greater than $0.1 \mathrm{ng} / \mathrm{ml}$. Patients with plasma troponin T concentrations greater than $0.01 \mathrm{ng} / \mathrm{ml}$ $(\mathrm{n}=12)$ had greater delta systolic pressure values $(142 \pm$ $50 \mathrm{mmHg}$ versus $99 \pm 20 \mathrm{mmHg}, \mathrm{p}=0.026)$, greater delta mean blood pressure values $(106 \pm 39 \mathrm{mmHg}$ versus $76 \pm$ $20 \mathrm{mmHg}, \mathrm{p}=0.056)$ and were older $(54.7 \pm 14.7$ versus $36.2 \pm 15.1$ years, $\mathrm{p}=0.01$ ) than patients with troponin $\mathrm{T}$ levels $<0.01 \mathrm{pg} / \mathrm{ml}$. Troponin $\mathrm{T}$ was inversely associated with systolic pressure $(\mathrm{r}=-0.53, \mathrm{p}=0.01)$ during autonomic instability period. 
EKG findings performed at different time points were similar to baseline EKG (including the fact that no new $Q$ waves were identified), except for arrhythmias.

\section{Transthoracic two-dimensional echocardiography}

Transthoracic two-dimensional echocardiography with Doppler was performed at the bedside during autonomic instability. In some patients, important variations of blood pressure occurred during the echocardiograms, but LVEF values remained within normal limits. The exam was repeated in the echocardiography laboratory under optimal conditions, after recovery from tetanus. Mean ejection fraction measured during autonomic instability and in the recovery period was $67 \pm 7 \%$ and $65 \pm 7 \%$, respectively $(\mathrm{p}=0.41)$.

\section{Discussion}

In this study in severe tetanus, all patients had autonomic instability characterized by cardiac arrhythmias, blood pressure instability, and/or cardiac arrest. However, these findings were not associated with increase in plasma catecholamine levels or in biological markers of inflammatory response. In spite of an increase in levels of the myocardial damage marker troponin $\mathrm{T}$ in 12 patients, this was not associated with cardiac dysfunction, as assessed by LVEF.

\section{Autonomic instability and plasma catecholamines}

In our study, plasma catecholamine levels were within normal ranges during autonomic instability; in fact, mean levels tended to be higher after recovery from tetanus. Autonomic instability in tetanus suggests intense sympathetic activity [4]; this has been associated with high catecholamine, mainly norepinephrine, levels [9,10,22]. However, some case reports showed contradictory results, reporting elevated [3,23] or normal [6] levels of urinary catecholamine excretion. A case report of one patient, where catecholamines were measured in a hourly basis, showed increase in catecholamine levels during hypertensive periods and normal levels when blood pressure was normal. Urinary levels were normal too [22]. Another study showed increased levels of catecholamines in three patients during periods of hypertension, but the patient who was under curare had near normal catecholamine levels [5]. Differently from our approach, others have measured urinary levels of catecholamines, observing both normal or elevated levels $[3,6,23]$. From the above studies, measuring either urinary or plasma levels of catecholamines in patients with tetanus, no definite consensus can be determined as to which is the best approach. As during autonomic instability, variation of blood pressure can be very rapid, we chose to measure catecholamines using HPLC, considered a sensitive detection method, in only one moment, which could be temporally associated or not with hypertensive peaks. However, we did not observe increase in catecholamine levels when blood pressure values were at their peak

Normal catecholamine concentrations observed during autonomic instability may also be explained by the pharmacological treatment and resources available nowadays in ICUs, which allow the patient to be kept under deep sedation to control spasms and under adequate mechanical ventilation. Thus, our findings cannot be truly compared to previous reports mentioned above regarding catecholamine levels $[3,22,23]$, mainly because availability of treatment strategies was markedly different. After recovery from tetanus, without anesthesia and under normal conditions, plasma catecholamines may have returned to their usual concentrations; therefore higher than those from the autonomic instability period. Alternatively, other authors postulate that vasomotor disorders in severe tetanus results from changes in systemic vascular resistance secondary to the involvement of the central nervous system $[12,13,24]$. An alternative would be that autonomic dysfunction in tetanus may not be mediated by plasma catecholamines but neurally, and therefore not reflected by plasma catecholamines levels. In fact, catecholamines activity is complex and involves a multistep G-proteins, protein kinase C, cAMP and phosphodiesterase actions. Coupling between these components appears to be highly modulable [25]. Interestingly, evaluation of autonomic nervous system function with spectral analyses of heart rate variability in a case of tetanus, recently revealed profoundly decreased activity of both sympathetic and parasympathetic modulation of cardiac rhythm, but with predominant parasympathetic nervous system impairment [26].

\section{TNF- $\alpha$ levels}

In this study, levels of TNF- $\alpha$ were not above expected normal limits. To our knowledge, no previous studies attempted to characterize cytokine profile in patients with tetanus, which limits our ability to compare ours to findings from others. Our group, as well as others, has shown that TNF- $\alpha$ levels are increased in the context of sepsis [27]. In this study some patients had documented infection although sepsis criteria were difficult to determine because of autonomic instability. However, patients with tetanus are not fully comparable to patients with sepsis, as tetanus is characterized by an intoxication of the central nervous system by the tetanic toxin, not necessarily an infectious process related/associated with sepsis. An alternative hypothesis was that potentially elevated cytokines in the setting of tetanus could be related to myocardial damage caused by excessive and continuous sympathetic drive [9]. However, in our study no such excessive production of catecholamines was found, further restraining possible sources of increased TNF- $\alpha$. 


\section{Troponin T levels}

In our series, most patients had elevated levels of this marker but no new $\mathrm{Q}$ waves were observed in the EKGs performed afterwards. Few reports in experimental in vitro models of tetanus have demonstrated increased traditional cardiac enzymes [28]. This is the first time (to our knowledge) that troponins are evaluated in the setting of tetanus; on the other hand, these markers are described to be elevated even in healthy individuals after extraneous physical activity [29], probably indicating some degree muscle damage. Likewise, in our patients it is possible that some degree of myocyte damage occurred but perhaps not clinically relevant to produce noticeable $\mathrm{Q}$ waves at the EKG. However, we observed an inverse association of troponin $\mathrm{T}$ and systolic pressure, a positive association with diastolic pressure and mean blood pressure variations, suggesting that pressure instability contributed to elevation of troponin $\mathrm{T}$ in these patients. Similarly, findings of increased troponins in sepsis have also been found to be associated with duration of hypotension, but not with areas of necrosis by EKG findings [30]. Therefore, our data may suggest that as in SIRS events and in sepsis, blood pressure instability may influence the elevation of troponin concentrations without myocardial necrosis in tetanus.

\section{Left ventricular ejection fraction}

In our study, echocardiography evaluation during autonomic instability failed to identify systolic ventricular dysfunction or regional contractility abnormalities. In spite of the occurrence of variable values of blood pressure during echocardiography, practically all patients maintained normal ejection fraction, indicating a well preserved cardiac reserve in this setting. These findings were confirmed by transthoracic echocardiography performed under ideal conditions after recovery from tetanus. These observations were compatible with the absence of ischemic or necrosis areas by EKG, in spite of elevated troponin T levels.

Previous studies of severe tetanus with autonomic instability suggested the occurrence of myocardial dysfunction secondary to myocardial necrosis caused by tetanic toxin and to elevated catecholamine concentrations $[4,8,11,31$ 33]. A study using invasive hemodynamic assessment showed a profile compatible with hyperdynamic response [14]. Although invasive assessment of cardiac function may not be methodologically comparable to echocardiography-based evaluation, our data, nonetheless, indicate that cardiac function was in fact preserved during autonomic instability, not necessarily reflecting an hyperdynamic pattern, since in both autonomic instability and after tetanus recovery similar/normal values for LVEF were observed.

\section{Limitations of the study}

Only one measurement of catecholamine and TNF- $\alpha$ concentrations was performed during the autonomic instability period, which may not have coincided with the peak of release of these substances. However, according to previous reports available $[4,5,22,23]$ we assumed that significant increases in catecholamine levels were present during the entire autonomic instability period. Serial measurements could have provided different results.

\section{Conclusion}

In patients with severe tetanus, during the period of autonomic instability, our data failed to demonstrate the presence of increased levels of catecholamines or the presence of cardiac dysfunction. Thus, our data do not support the hypothesis that autonomic disturbances in tetanus are secondary to adrenergic variations or cardiac dysfunction. Additionally, it may be suggested that within-normal limits levels of catecholamines in the autonomic instability period may be explained by overblurred of the autonomic system in tetanus.

We speculate that additional mechanisms, perhaps of central origin, may play more important roles in the pathogenesis of autonomic dysfunction in tetanus, and that levels of catecholamines and cardiac dysfunction contribute less importantly. Experimental studies are required to further elucidate cause-effect relationship between these events in tetanus.

\section{List of abbreviations}

APACHE II = Acute Physiology and Chronic Health Evaluation II

$$
\begin{aligned}
& \text { ECLIA = electrochemiluminescence immunoassay } \\
& \text { EKG = electrocardiogram } \\
& \text { HPLC = high performance liquid chromatography } \\
& \text { ICU = intensive care units } \\
& \text { LVEF = left ventricular ejection fraction } \\
& \text { TNF = tumor necrosis factor }
\end{aligned}
$$

\section{Authors' contributions}

JSB participated in study conception, data collection, data analysis and drafting.

NC participated in study conception, study design and coordination, and drafting.

Both authors have read and approved the final version of the manuscript. 


\section{References}

I. Farrar JJ, Yen LM, Cook T, Fairweather N, Binh N, Parry J, Parry CM: Tetanus. J Neurol Neurosurg Psychiatry 2000, 69:292-30I.

2. Brauner JS, Vieira SRR, Bleck TP: Changes in severe accidental tetanus mortality in ICU during two decades in Brazil. Intensive Care Med 2002, 28:930-935

3. Kerr JH, Corbett JL, Prys-Roberts C, Smith AC, Spalding JM: Involvement of the sympathetic nervous system in tetanus. Lancet | 968, 2:236-24I.

4. Clifton B: Hypotension associated with tetanus. Lancet 1964, I:785-788.

5. Kelty SR, Gray RC, Dundee JW, McCullouch H: Catecholamine levels in severe tetanus. Lancet 1968, 2:195.

6. Pearce DJ: Proceedings of a symposium on tetanus in Great Britain Edited by: Ellis M. Leeds, Great Britain; 1967:31.

7. Ambasche N, Lippold $\mathrm{OCH}$ : Bradycardia of central origin produced by injections of tetanus toxin into the vagus nerve. J Physiol 1949, I08:186-196.

8. Tsueda K, Oliver PB, Richter RW: Cardiovascular manifestations of tetanus. Anesthesiology 1974, 40:588-592.

9. Raab W, Krzywanek HJ: Cardiovascular sympathetic tone and stress response related to personality patterns and exercise habits - a potential cardiac risk and screening test. Am J Cardiol 1965, 1 6:42-53.

10. Moss AJ, Vittands I, Schenke EA: Cardiovascular effects of sustained norepinephrine infusions. I. Hemodynamics. Circ Res 1966, I 8:596-604

II. Vakil BJ, Mokashi JM, Tulupule TH: Cardiocirculatory disturbances in tetanus. A clinical experimental study. In Proceedings of the Ist International Conference on Tetanus Edited by: Patel J. Bombay; 1965:255-276.

12. James MFM, Manson EDM: The use of magnesium sulphate infusions in the management of very severe tetanus. Intensive Care Med 1985, I I:5-12.

13. Cook TM, Protheroe RT, Handel JM: Tetanus: a review of literature. BrJ Anaesth 200I, 87:477-487.

14. Udwadia FE, Sunavala JD, Jain MC, D'Costa R, Jain PK, Lall A, Sekhar M, Udwadia ZF, Kapadia F, Kapur KC, et al.: Hemodynamic studies during the management of severe tetanus. $Q J$ Med 1992, 83:449-460.

15. Satoh M, Nakamura M, Saitoh H, Satoh H, Maesawa C, Segawa I, Tashiro A, Hiramori K: Tumor necrosis factor alpha converting enzyme and tumor necrosis factor alpha in human dilated cardiomyopathy. Circulation 1999, 99:3260-3265.

16. Kubota T, Miyagishima M, Alvarez RJ, Kormos R, Rosenblum WD, Demetris AJ, Semigran MJ, Dec GW, Holubkov R, McTiernan CF, et al.: Expression of proinflammatory cytokines in the failing human heart: comparison of recent-onset and end-stage congestive heart failure. J Heart Lung Transplant 2000, 19:819-824.

17. Abblett JJL: Analyses and main experiences in 82 patients treated in the Leeds Tetanus Unit. In Symposium on tetanus in Great Britain Edited by: Ellis M. Boston: National Lending Library; 1967: 1-10.

18. Bleck TP, Brauner JS: Tetanus. In Infections of the central nervous system 2nd edition. Edited by: Scheld RJW, Durack DT. Philadelphia: Lippincot-Raven; 1997:629-653.

19. Baum $\mathrm{H}$ : Evaluation and clinical performance of a second generation cardiospecific assay for troponin T. Clin Chem 1997, 43: $1877-1884$

20. Roche Diagnostics Corporation: International Elecsys 1010 study, cardiac markers. In Troponin T STAT (short turn around time), cardiac T Indianapolis; 1999.

21. Christenson RH, Duh SH, Newby LK, Ohman EM, Califf RM, Granger CB, Peck S, Pieper KS, Armstrong PW, Katus HA, et al.: Cardiac troponin $T$ and cardiac troponin I: relative values in short-term risk stratification of patients with acute coronary syndromes. Clin Chem 1998, 44:494-50I.

22. Domenighetti GM, Savary G: Hyperadrenergic syndrome in severe tetanus: extreme rise in catecholamines responsive to labetalol. BM] | 984, 288: |483-| 484.

23. Kanerek DJ, Kaufman B, Zwi S: Severe sympathetic hyperactivity associated with tetanus. Arch Intern Med 1973, 132:602-604.

24. Toothill C, Dykes JRW, Ablett JlL: Urinary catecholamine metabolites concentrations in tetanus. $\mathrm{Br} J$ Anaesth 1970, 42:524-530.
25. Majewski H, lanazzo L: Protein kinase C: a physiological mediator of enhanced transmitter output. Prog Neurobiol 1998, 55:463-475.

26. Goto T, Fukushima H, Sasaki G, Matsuo N, Takahashi T: Evaluation of autonomic nervous system function with spectral analysis of heart rate variability in a case of tetanus. Brain Dev 200I, 23:791-795.

27. Ammann P, Fehr T, Minder El, Gunter C, Bertel O: Elevation of troponin I in sepsis and septic shock. Intensive Care Med 200I, 27:965-969.

28. Lundsgaard-Hansen P, Stirnemann H, Richterich R: Srumenzymveraenderungen bei klinischem un experimentellem tetanus. Helv Chir Acta 1966, 33:5-8.

29. Neumayr G, Pfister R, Mitterbauer G, Maurer A, Gaenzer H, Sturm W, Hoertnagl H: Effect of the "Race Across the Alps" in elite cyclists on plasma cardiac troponins I and T. Am J Cardiol 2002, 89:484-486.

30. Arlati S, Brenna S, Prencipe L, Marocchi A, Casella GP, Lanzani M, Gandini C: Myocardial necrosis in ICU patients with acute non-cardiac disease: a prospective study. Intensive Care Med 2000, 26:3।-37.

31. Lassen HC, Bjorneboe M, Ibsen B, Neukirch F: Treatment of tetanus with curarisation, general anaesthesia, and intratracheal positive-pressure ventilation. Lancet 1954, I I : I040- I 044.

32. Alhady SMA, Bowler DP, Reid HA: Total paralysis regimen in severe tetanus. BMJ 1960, I:540-546.

33. Kloetzel K: Clinical patterns in severe tetanus. JAMA I963, I 85:559-567.
Publish with Bio Med Central and every scientist can read your work free of charge

"BioMed Central will be the most significant development for disseminating the results of biomedical research in our lifetime. "

Sir Paul Nurse, Cancer Research UK

Your research papers will be:

- available free of charge to the entire biomedical community

- peer reviewed and published immediately upon acceptance

- cited in PubMed and archived on PubMed Central

- yours - you keep the copyright

Submit your manuscript here:

http://www.biomedcentral.com/info/publishing_adv.asp
BioMedcentral 